\title{
WOULD U LIKE THIS IMPLANT TO BE USED ON YOUR HIP
}

Nandivada V .S. Kiran Kumar

1. Orthopaedic Surgeon. Department of Orthopaedics, Krushi Orthopaedic Welfare Society.

\section{CORRESPONDING AUTHOR:}

Nandivada V .S. Kiran Kumar, 50-54-1/1, P \& T Colony, Seethammadhara, Visakhapatnam.

Andhra Pradesh, India.

E-mail: drkiranindia@gmail.com

ABSTRACT: AIM : to highlight the urgent need for increasing the awareness of operation theater staff regarding the importance of sterile procedures and proper handling of implants in the OTs before and after the surgical usage as the loose implants rotate from hospital to hospital collecting a lot of contamination on the way ,,, as they are supplied to every caller. OBJECTIVE: to prevent post operative infections which may ruin a life due to many endless debriding surgeries or may end the life in a permanent lifelong infection, amputation, or loss of precious life due to sepsis or suicide due to frustration or financial implications and social problems .

DISCUSSION: OT sterile protocol is mandatory and followed by all OT staff and doctors around the world in India also this is a must and is being followed but in this hospital OT, this picture is a grim reminder of the staff's negligence and inhumanness calling for a total recall of his or her posting with immediate effect and sending the persons in charge of the OT to basic OT training course . Infections in orthopaedics are predominantly caused by staphylococcus aureus besides many more dangerous bacteria, etc the prevalence of a concept called as " bio film " on a infected implant is well known and poor penetration of the antibiotics into the bio film is also very well known ....meaning it is a hell for the patient and the treating surgeon if infections occur

\section{CONCLUSION:}

*prevention is better than cure.

* lets all implement the OT protocols of the developed world and let us all increase OT sterile awareness by conducting training programmes for doctors, OT staff and all concerned paramedical staff on a regular basis .

* Lets use only packed sterile implants in the future as seen in this picture below.

AUTHOR'S COMMENT:please believe me when i say this " all loose implants are contaminated from outside and all cannulated instruments and screws may have bone or dirt inside. So ortho surgeons must think twice before ordering a loose ,unsterile implant ..because when i stopped using them why cant others?..

\section{REFERENCES:}

1. mor-of.net/article_services_tdegross_surgical_center_cleaning...

2. the american institute of architects and the facilities guidelines institute. guidelines for design and construction of hospital and health care facilities, 2001. washington, dc: american institute of architects press, 2001. 
3. arnow pm, sadigh $\mathrm{m}$, costas c, weil d, chudy $\mathrm{r}$. endemic and epidemic aspergillosis associated with in-hospital replication of aspergillus organisms. j infect dis 1991;164:998--1002.

4. streifel aj. design and maintenance of hospital ventilation systems and the prevention of airborne nosocomial infections [chapter 80]. in: mayhall, cg, ed. hospital epidemiology and infection control. $2^{\text {nd }}$ ed. philadelphia, pa: lippincott williams and wilkins, 1999.

5. pittet $d$, huguenin $t$, dharan $s$, et al. unusual cause of lethal pulmonary aspergillosis in patients with chronic obstructive pulmonary disease. am j respir crit care med 1996;154(2 pt 1):541--4.

6. us environmental protection agency, office of air and radiation, and us department of health and human services, national institute of occupational safety and health. building air quality: a guide for building owners and facility managers. washington, dc: 1991; dhhs publication (niosh)91-114 and epa/400/1--91/033. available at http://www.cdc.gov/niosh/baqtoc.html.

7. rao cy, burge ha, chang jc. review of quantitative standards and guidelines for fungi in indoor air. j air \& waste manage assoc 1996;46:899--908.

This photograph is from a government hospital handling major trauma including replacements but it is so unethical to find these unsterile and loose implants crying for help and safe packing as they lay gathering dust, bacteria from ledgers and almirah dust .. All OT handling precautions are left to the winds here.
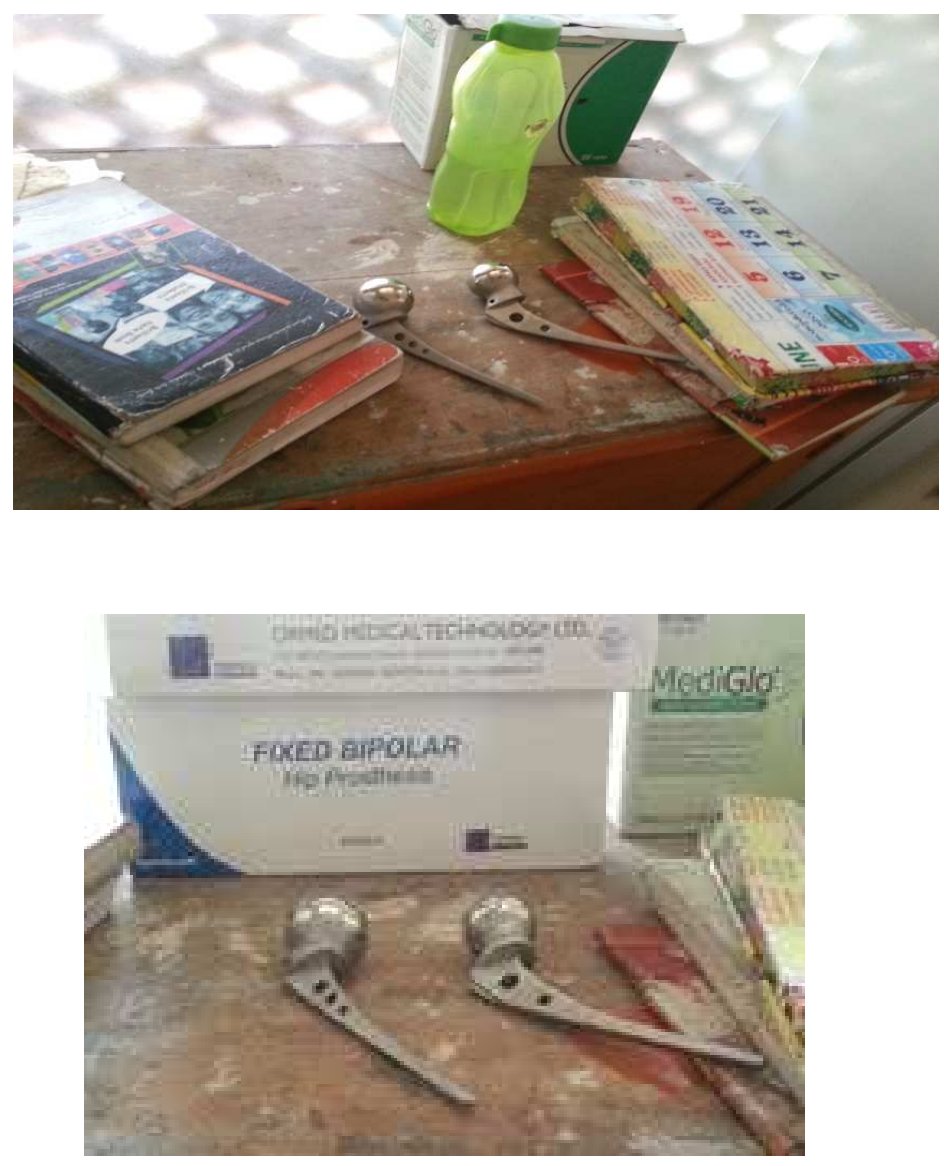